\title{
Erratum
}

To the paper

\section{Determination of polonium-210 in phosphoric acid}

\section{T. Nakanishi, ${ }^{1 *}$ H. Fukuda, ${ }^{2}$ M. Hirose ${ }^{1}$}

'Department of Chemistry, Faculty of Science. Kanazawa University, Kakuma-machi, Kanazawa, Ishikawa 920-1192, Japan

${ }^{2}$ Nano-electronic Materials Research and Engineering Laboratory, Fujitsu Laboratories Ltd., 10-1, Morinosato Wakamiya, Atsugi, Kanagawa 243-0197, Japan

(Received September 4, 1998)

appeared in the Journal of Radioanalytical and Nuclear Chemistry, Vol. 240, No. 3 (1999) 887-891. On pages 889 and 890, Fig. 1 and Fig. 3 are misplaced with each other. The caption of Figs 1 and 3 are in the right order. 